\title{
Adhesion Factor Degradation Process
}

National Cancer Institute

\section{Source}

National Cancer Institute. Adhesion Factor Degradation Process. NCI Thesaurus. Code C40674.

By induction of conjugation, transport, oxidation, and/or proteolysis, Adhesion Factor Degradation consists of breakdown of members of the class of cell surface proteins involved in cell-cell or cell-matrix attachment. 